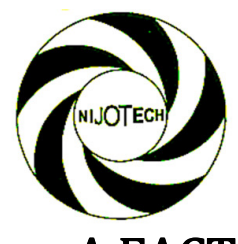

Nigerian Journal of Technology (NIJOTECH)

Vol. 35, No. 1, January 2016, pp. 71 - 79

Copyright@ Faculty of Engineering, University of Nigeria, Nsukka,

Print ISSN: 0331-8443, Electronic ISSN: 2467-8821

www.nijotech.com

http://dx.doi.org/10.4314/njt.v35i1.12

\title{
A FACTORIAL STUDY OF CORPORATE PERFORMANCE OF NIGERIAN REFINERIES
}

\author{
A. C. Igboanugo', 0. M. Garba² and T. I. Okafor ${ }^{3}$ \\ 1, 2,3Department of Production Engineering, University of Benin, Benin City, Edo State, NiGERia \\ E-mail addresses: ${ }^{1}$ anthony.igboanugo@uniben.edu, ${ }^{2}$ maikasombu@yahoo.com,3izunnaokafor@gmail.com
}

\begin{abstract}
Realizing that the Nigerian refineries are dysfunctional and therefore are unable to meet the optimal production output, a survey was undertaken as to identifying and ascertaining the inter correlations among a range of variables that influence the operation of the Nigerian refineries. Accordingly, a statistical approach, involving a combined use of Kendall's coefficient of concordance, which ranks variables in merit order sequentiality, and Principal Component Analysis (PCA), that tries to perceive similarity in dissimilarity by achieving parsimony through factor reduction, was adopted. Our results show that a null hypothesis claiming that the ranking of the range of factors by forty (40) judges is discordant was rejected at a p-value of 0.05 , thus suggesting that the computed index of consistent ranking (coefficient of concordance $W=0.56909$ ) is a middling. Besides, the PCA deployed was successful in achieving parsimony by clustering a plethora of sixty-one (61) variables into mere nineteen (19) collections or enfoldments. To boot, an outstanding sturdy cluster wielding remarkable positive factor loadings, which was creatively labelled omnium-gatherum came up trumps as most significant and it's quite needful as policy instrument. Thus, if NNPC is to square away (neaten up) the dysfunctionality alluded to at the outset and have to nudge their operations towards a decent future, this paper importunes that the omnium-gatherum, in the first instance, needs to be factored into their aggregate planning.
\end{abstract}

Key words: Omnium-gatherum, Principal Component analysis, Coefficient of Concordance, Refinery, Subsidy.

\section{INTRODUCTION}

Nigeria operates four refineries that contribute to a gross output of about 222.5 bpd of crude out of the 445 bpd of installed capacity $[1,2]$. The current output which still fluctuates widely is considered grossly inadequate to meet the total demand of about 35 million litres per day of premium motor spirit (P.M.S). Consequently, the nation is as it were, pushed to the precipice of energy crises that has manifested in frequent acute shortage of petroleum products, a situation that is in itself rather embarrassing, being the seventh oil producer in the world.

There are oodles of factors that contribute to this kind of anomaly. Among others, they include inadequate manpower planning, operational dysfunction, paucity of innovative drive, re-engagement of retired staff on contract basis, exportation of crude oil and subsequent buying back of the refined products, as well as approval and payment of subsidy by government. There are more offending reasons why the refinery is malfunctioning, but space forbids their inclusion.

This research is considered paramount at this point in time because it is embarrassing to hear that a nation that is ranked seventh in the world oil output is being seen by the outside world as a banana republic that is characterized by exporting raw materials (crude oil in this case) and then goes to buy back the bye products to satisfy its domestic needs. Moreover, it is important that exhaustible resource should be judiciously used in such a manner that the proceeds from the utilization would be ploughed back for the establishment of heavy industries that will in turn become sources of income generation that will be relied upon when the natural resource would have depleted.

As it were, now, petroleum appears to be an albatross on the neck of government because by mismanaging the resources, it has become a burden that hinders our progress. For instance, economic activities are 
hampered by fuel scarcity and where you find it to buy it is at a prohibited cost. This situation has lingered and is still lingering A number of studies has examined a range of problems associated with the conversion of crude oil into end products and found that they are multi-facetted. However, update research in this field reveals that the balance of literature is glaringly deficient on the combined use of Kendall coefficient of Concordance and a brand of Factor Analysis, Principal Component Analysis (PCA), as analytics in researching the problem.

The current study breaches this frontier of knowledge by applying the combination of these two models as to have a bird's-eye-view, not worm's view of the problem. Accordingly, the combined model is seemly and adequate as against others that seem to be like viewing the problem from a low position.

Vast literature related to upstream, midstream and downstream of oil sectors abound. Specifically, efforts to address the problem of refinery operation has been carried out by many researchers. Petroleum refining is undoubtedly one of the most complex chemical industries. The Study [3] examined the complex nature of refineries comprising many different and complicated processes with various possible configurations and structures. Several attempts had been made to improve refinery output. Globally, the demand for petroleum products will continue to increase. It was opined from a study that the global demand for petroleum products will increase from 77.1 million barrel per day (mbpd) in 2001 to 118 mbpd in 2025[4]. This has encouraged many operators in refineries business to improve the quality of products output through crude blending as observed by [5]. In Nigeria, the effect of petroleum shortages occasioned by poor performance of the Nigerian refineries was studied by [6]. In the research, a projection for petroleum products supply and energy demand was highlighted and necessary steps needed to be taken to meet the projection were outlined as a way forward. Successive administrations have made effort in order to ensure adequate supply of petroleum products in Nigeria, unfortunately, this problem persist. It was recommended in a research study by [7] that as a first step in overcoming the shortages of petroleum products supply, all domestic refineries must be put in full productive capacity. Significant efforts have been made by $[8,9]$ on the application of Linear Programming and Mixed Integer Linear programming models to investigate refinery planning and optimization.
Relatedly, a Mixed Linear Programming approach as it applies to refinery optimization was carried out by [10]. More recently, [11] had studied the inherent risks associated with Nigerian Marginal oilfields and provide useful insight on how to mitigate risks to unlock economic potential of the marginal oil field. Further, modelling of refinery production, planning and scheduling to enhance operational efficiency is credited to [4]. Furthermore, [12] addressed the problem of refinery planning under uncertainty using applied stochastic optimization. The study [13] applied mathematical programming in optimizing operations in petroleum refineries while [14] takes a cursory study on how best our refineries can be deregulated to achieve optimal performance of the industry.

Again, safety of operators and equipment is of great essence in refinery operation as it enhances production output and reduces as reasonably practicable, the effect of hazard to operators. One of the latest researches on this is credited to [15] who carried out detailed safety evaluation and analysis of Naphtha Hydro-treating unit (Nhu) of the Kaduna Refining and Petrochemical Company to ascertain the safety level of the unit's operation. The study concluded by suggesting proactive control measures to be implemented to reduce safety and occupational health hazard. Moreover, maintenance of refinery is a key success factor for optimal output as seen in [16]. The investigation focused on how best refineries can be maintained to reduce the down time due to pressure on the equipment. The result revealed that Reliability Centred Maintenance (RCM) is popular among other methods in achieving continued improvement in reliability of equipment. It is noted that Refineries equipment are always overstretched due to continuous operation. The study [17] reported on how best refineries can overcome the problem of equipment stretch and concluded that debottlenecking can enhance the efficiency and effectiveness of the refinery. Similar study was carried out by [18] who analysed the criteria used in the industry for measuring the performance of petroleum refineries and recommended management intervention model for tracking trends of development. The paper [19] studied the uncertainty of refinery using Hybrid of Stochastic Programming Approaches with Economic and Operational Risk Management. Nigerian refineries have become cost centre $[2,18]$ and effort is needed to correct this anomalies, the paper noted. Besides, several research 
studies credited to $[14,12,13$ and 14$]$ were carried out to evaluate the administration of subsidy payments by the Federal Government. Similarly, [20] observed that subsidies on petroleum products rose from N70 billion in 2003 to N450 billion in 2006, furthermore, in 2008, it was increased to over N1.5 trillion naira which can fund a capital budget in a year. The NNPC online report also stated that, in order to meet the deficit in petroleum products supply (premium motor spirit, kerosene and Automotive gas oil) in 2012 alone, Nigeria spends between $\$ 12$ and $\$ 15$ billion (United States Dollars) for importation. The economic benefit of a nation refining in excess of its demand is quite enormous. Therefore, over dependence of imported petroleum products is a burden that cannot be carried for too long [21]. Arising from the foregoing sample review, it is clear that the balance of literature is deficient on the use of elaborate analytics to analyse the dysfunctionality of the Nigerian refineries. This paper supplies the essential.

The aim of this study is to conduct a survey of a diversity of factors that impact on the performance of oil refining functions in Nigeria. And having identified these factors, to further examine the interplay among them so that through such knowledge and understanding of the dynamics, policy variables can be articulated to guide the operators of the refinery on the optimal plan to follow in order to achieve effectiveness and efficiency in their operations. This has become imperative because resources have to be well managed and utilized for the growth and development of the Nigerian economy. Natural resources like the crude oil deposit is an endowment from nature and it is exhaustible. Therefore, optimal utilization is needed so that proceeds from such sector can be reinvested for future utilization when the resources are depleted

\section{METHODOLOGY}

\subsection{Research Design}

The game plan adopted in this research setting involves a general survey of attitudes of refinery workers towards crude refining. The population is the total workforce in Nigeria refineries. However, a stratified sampling comprising Kaduna Refining and Petrochemical Company (KRPC), Warri Refining and Petrochemical Company (WRPC), and part of the academia represented by Federal University of Petroleum Resources, Effurun (FUPRE) were taken as our sampling units. abstracted from a wide survey of past studies were used to craft a set of questionnaire that were administered to ruddily knowledgeable respondents selected from the sampling units of the Nigerian refineries and Federal University of Petroleum Resources, Effurun (FUPRE). Altogether, 150 sets of questionnaire were administered and 118 were retrieved. Respondent's scores were collated as data matrix and fed into StatistiXL software that provided the following output:

i. scree Plot

ii. eigen value and eigen vectors

iii. factor loadings, and

iv. descriptive statistics

These outputs guided the subsequent interpretations that were rendered.

Previous to this, the sixty-one scale items were referred to 40 judges who ranked them in the descending order of importance. The consistency in ranking is represented by Kendall's coefficient of concordance and chi square $\left(\chi^{2}\right)$ statistic was used to appraise how consistent the judges were in ranking the scale items.

The detail of the application of the coefficient of concordance is sketched hereunder.

a Let $\mathrm{N}$ be the number of scale items to be ranked and let, $\mathrm{k}$ be the number of judges assigning ranks.

b. Cast the observed rank into $\mathrm{K}^{*} \mathrm{~N}$ matrix

c. For each entity obtain $R_{j}$, which is the total scores of each of the scale item

d. Obtain the mean of the various $R_{j}$ 's, where $j$ refers to the variable response or stimulus from the judges on scale item, $\mathrm{i}$

e. Obtain the deviation of every $R_{j}$ from the calculated mean of $\mathrm{R}_{\mathrm{j}}$

f. Obtain the square of the deviation of each of the scale items

g. The Kendall Coefficient of Concordance (W), which measures the degree of agreement between the judges is obtained from the equation (1)

$$
\begin{aligned}
& W \\
& =\frac{12 S}{K^{2}\left(N^{3}-N\right)}
\end{aligned}
$$

where $\mathrm{S}=\sum\left(R_{j}-\sum R_{j} / N\right)^{2}=$ Rank variance See [22] for detailed information on the application of the Coefficient of Concordance.

\subsection{Test of Hypothesis}

Here, we put forward the following hypotheses: $\mathrm{H}_{\mathrm{o}}$ : The rankings of the 40 judges are discordant

Vol. 35, No. 1 January 2016 
$\mathrm{H}_{1}$ : The judges are using the same standard in ranking.

Since $\mathrm{N}$ is essentially large, we apply $\chi^{2}$-test statistic to ascertain the significant level of $\mathrm{W}$ calculated.

Clearly, $\chi^{2}=\mathrm{k}(\mathrm{N}-1) \mathrm{W}$, and if $\chi_{\text {cal. }}^{2}>\chi_{\text {tab. }}^{2}$, fail to accept the null hypothesis.

\subsection{Abridge Theory of the Application of the Principal Component Analysis (PCA)}

Let $\mathrm{X}_{\mathrm{ij}}$ and $\mathrm{Y}_{\mathrm{ij}}$ represent a pair of variables in the data matrix.

Define column mean as

$$
\bar{X}_{j}=\sum_{i=j}^{N} \frac{X_{i j}}{n_{j}} \text { and } \bar{Y}_{j}=\sum_{i=j}^{N} \frac{Y_{i j}}{n_{j}}
$$

Then

$$
x=X_{i j}-\bar{X}_{j} \text { and } y=Y_{i j}-\bar{Y}_{j}
$$

Where $\mathrm{i}$ and $\mathrm{j}$ refers to the state of the matrix, $\mathrm{x}$ and $\mathrm{y}$ refers to the respective mean deviation or deviation from the mean

Hence, the Correlation coefficient, $r_{i j}$ is defined as

$$
r_{i j}=\frac{\sum x y}{\sqrt{\left(\sum x^{2}\right) \cdot\left(\sum y^{2}\right)}}
$$

When $r_{i j}$ is computed for every pair from the whole lot of ${ }^{\mathrm{n}} C_{2}=\frac{n !}{(n-2) ! 2 !}$. We then collate same into a correlation matrix which forms the first input into Factor Analysis.

StatistiXL software is then used to generate output such as:

i. Descriptive Statistics

ii. Communalities

iii. Factor Loading

iv. Eigen values and Eigen vectors

\section{RESULT}

From tables 1 and 2,

$\sum R_{j}=79200$

$\left[\frac{\sum R_{j}}{N}\right]=79200 / 61=1298.361$

$S=\sum\left(R_{j}-\frac{R_{j}}{N}\right)^{2}=17218503.35$

$\mathrm{W}=17218503.35 /\left[(1 / 12) * 40^{2}\left(61^{3}-61\right)\right]$

$=17218503.35 / 30256000$

$=0.569093$

$\chi^{2}=\mathrm{K}(\mathrm{N}-1) \mathrm{W}=40(61-1) 0.569093=1365.8252$

$(\mathrm{N}-1)$ is the degree of freedom, $\mathrm{H}_{0}$ : The rankings of the 40 judges are discordant, $\mathrm{H}_{1}$ : The judges are using the same standard in ranking.

At 0.05 significant level, $\chi^{2}=79.08$ at 0.1 significant level, $\chi^{2}=74.4$

$$
\begin{aligned}
\chi_{c a l}^{2}=1365.8252 & >\chi_{0.05}^{2}=79.08 \text { and } \chi_{c a l}^{2} \\
= & 1365.8252>\chi_{0.1}^{2}=74.4
\end{aligned}
$$

Table 1: Data matrix of the 61 scale items and sum of

\begin{tabular}{|c|c|c|c|c|c|c|c|}
\hline $\begin{array}{c}\text { Scale } \\
\text { items }\end{array}$ & 1 & 2 & 3 & 4 & $\ldots$ & 60 & 61 \\
\hline $\begin{array}{l}\text { Sum of } \\
\text { Ranks }\end{array}$ & 102 & 1447 & 1489 & 709 & $\ldots$ & 2131 & 481 \\
\hline
\end{tabular}

Table 2: Deviation of ranks from mean and the corresponding variance.

\begin{tabular}{cc}
\hline $\mathrm{R}_{\mathrm{j}}-\left[\frac{\sum \mathrm{Rj}}{N}\right]$ & $\left(\mathrm{R}_{\mathrm{j}}-\left[\frac{\sum \mathrm{Rj}}{N}\right]\right)^{2}$ \\
\hline-1196.36 & 1431279.642 \\
148.639 & 22093.55232 \\
190.639 & 36343.22832 \\
-589.361 & 347346.3883 \\
$\ldots$. & $\ldots$. \\
432.639 & 187176.5043 \\
-305.361 & 93245.34032 \\
137.639 & 18944.49432 \\
832.639 & 693287.7043 \\
-817.361 & 668079.0043 \\
Total & 17218503.35 \\
\hline
\end{tabular}

Table 3: Merit Order sequentiality of the Sixty-one Scale Items

\begin{tabular}{cl}
\hline S/No & ORDER OF SEQUENTILITY \\
\hline 1 & Funding Risk \\
2 & Cognate Training \\
3 & Technical Knowhow \\
4 & Pipelines Vandalism \\
5 & Equipment/tools inspection \\
6 & Poor Management commitment \\
7 & Gratification \\
8 & Equipment Reliability \\
9 & Political Vicissitudes \\
10 & Refinery Complete Automation \\
11 & Business Sustainability \\
12 & Safety Risk \\
13 & Adequate Manpower Plan \\
14 & Manpower Resource Availability \\
15 & Effective Supervision \\
16 & Explosion Risk \\
17 & Maintenance \\
18 & Paucity of investors \\
19 & Insecurity/ Terrorism \\
20 & Interest Rate \\
21 & Team work \\
22 & Loading / Unloading \\
23 & Operations Risk \\
24 & Infrastructure deficit \\
25 & Gas flaring \\
26 & Currency fluctuation \\
27 & Return on investment \\
\hline
\end{tabular}




\begin{aligned} & \hline S/No ORDER OF SEQUENTILITY \\ & \hline 28 Motivation \\ & 29 Obsolete equipment \\ & 30 Properties Acquisition \\ & 31 Technology Limitation \\ & 32 Changes in demand \\ & 33 Job satisfaction \\ & 34 Standard Operating Procedure \\ & 35 Environmental Regulations \\ & 36 Soaring Price \\ & 37 Interest Rates \\ & 38 Sanction \\ & 39 Competition Risk \\ & 40 Market volatility \\ & 41 Industry Policies \\ & 42 Turn Around Maintenance \\ & 43 Project Management Risk \\ & 44 Petroleum Process Technology \\ & 45 Population Encroachment \\ & 46 Cost of adequate Techniques \\ & 47 Process Safety \\ & 48 Choice of Outsourcing \\ & 49 Refinery Planning \\ & 50 Demand fluctuation \\ & 51 Maintenance Methodology \\ & 52 Manpower Recruitment \\ & 53 Partnering Alliance \\ & 54 Skills \\ & 55 Relevant Linkages \\ & 56 Manpower Planning \\ & 57 Effective Communication \\ & 58 Leadership Style \\ & 59 Reputation \\ & 60 Legal Risk \\ & 61 Fine \\ & \hline \\ & \hline\end{aligned}

\subsection{Result and Discussions}

The coefficient of concordance was computed as $\mathrm{W}=$ 0.569 , which is considered a middling. In order words, it is in the threshold of being substantial. The chisquare $\left(\chi^{2}\right)$ test at 0.05 and 0.1 significant levels show the critical values are 79.08 and 74.4 respectively. This inclined us to fail to accept the null hypothesis that the judges ranking is discordant. Our conclusion therefore is that the judges use the same criteria to do the ranking.

The correlation matrix as obtained with StatistiXL, is shown in Table 3. Figures 1 depicts the factor plot displaying the pattern of factor distribution. Figure 2 shows the eigen value. It's obvious from the scree plot that at eigen value of 1 , and component number 19, the curvity tends to flatten out, suggesting that nineteen factors extracted are adequate. This shows that there is significant parsimony in factor reduction
61 to 19 . We shall proceed now to discuss the 19 variable clusters

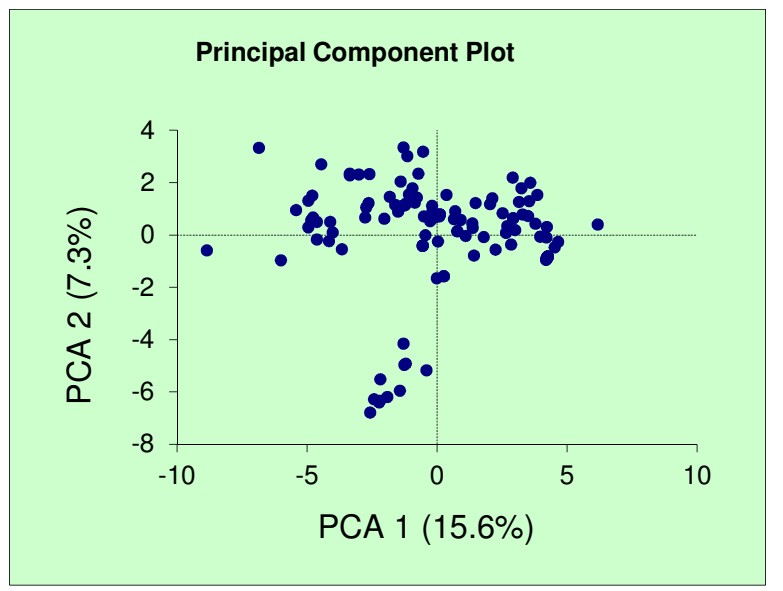

Fig. 1: Factor plot

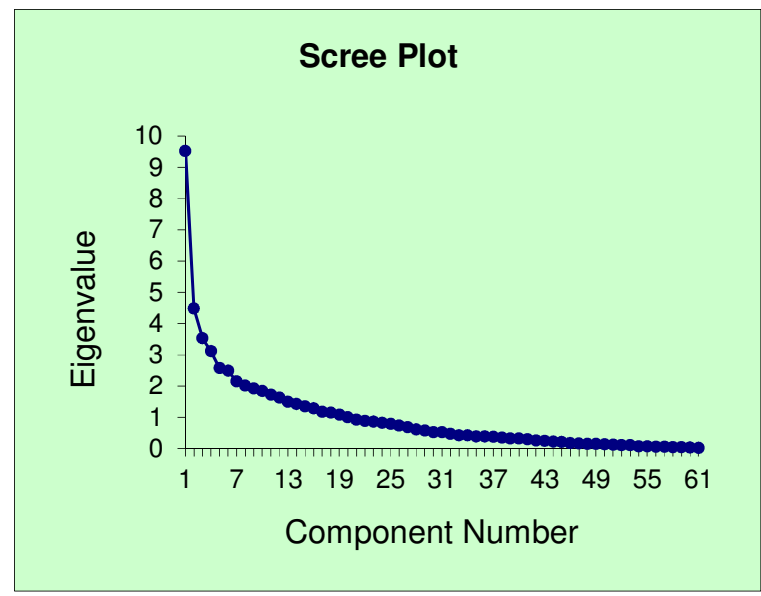

Figure 2: Eigen value

As can be seen from Table 4 that follows, the variables clustered therein comprises a collection of miscellaneous scale items which we have seemly creatively labelled omnium-gatherum.

The factor loadings are predominantly middlings and some moderate loadings. The magnitude of loadings indicates how important the scale item is within the cluster. As we can readily discern from the column vectors of loadings, they are all positive showing that omnium-gatherum cluster is a sturdy factor because none of them is negative. We shall take some samples of these variables to discuss their significance. For instance, scale item 13 wields a factor loading of 0.695 . The import is that the exchange rate between the dollar and naira, as far as refinery operations costing is concerned, is very paramount and indeed it is so. Most of the materials used in refining crude are imported and little local content are involved. There is the need therefore for the management to undertake 
innovative research to discover how alternative local raw materials can be used in refining.

Table 4: Omnium Gatherum PC1: OMIUM GATHERUM

\begin{tabular}{|c|c|c|}
\hline \multicolumn{3}{|c|}{ PC1: OMIUM GATHERUM } \\
\hline \multicolumn{3}{|c|}{$\begin{array}{c}\text { Factor Loadings (correlations between initial variables and } \\
\text { principal components. }\end{array}$} \\
\hline $\begin{array}{l}\text { SCALE ITEM } \\
\text { NO }\end{array}$ & SCALE ITEM & $\begin{array}{l}\text { COMPONENT } \\
\text { LOADINGS }\end{array}$ \\
\hline 4 & Business Sustainability & 0.574 \\
\hline 7 & Paucity of Investors & 0.433 \\
\hline 13 & Currency fluctuation & 0.695 \\
\hline 14 & Interest Rates & 0.433 \\
\hline 15 & Political Vicissitudes & 0.572 \\
\hline 17 & Properties Acquisition & 0.556 \\
\hline 20 & Gas Flaring & 0.509 \\
\hline 23 & Equipment Reliability & 0.631 \\
\hline 25 & Safety Risk & 0.624 \\
\hline 28 & Technology Limitation & 0.603 \\
\hline 31 & Refinery Planning & 0.507 \\
\hline 33 & $\begin{array}{lll}\text { Cost of adequate } \\
\text { techniques }\end{array}$ & 0.524 \\
\hline 34 & Infrastructure deficit & 0.618 \\
\hline 38 & $\begin{array}{ll}\text { Turn } & \text { Around } \\
\text { Maintenance } & \end{array}$ & 0.494 \\
\hline 41 & Operational Risk & 0.424 \\
\hline 42 & $\begin{array}{ll}\text { Standard } & \text { Operating } \\
\text { Procedure } & \\
\end{array}$ & 0.639 \\
\hline 43 & Cognate Training & 0.439 \\
\hline 44 & Manpower imbalance & 0.584 \\
\hline 46 & $\begin{array}{l}\text { Management } \\
\text { Commitment }\end{array}$ & 0.449 \\
\hline 51 & Leadership Style & 0.482 \\
\hline 53 & $\begin{array}{ll}\text { Manpower } & \text { Resource } \\
\text { Recruitment } & \\
\end{array}$ & 0.563 \\
\hline 57 & $\begin{array}{l}\text { Population } \\
\text { Encroachment }\end{array}$ & 0.488 \\
\hline
\end{tabular}

The next item is Standard Operating Procedure (SOP) with scale item number 42 which have a factor loading of 0.639 . And this scale item implies that the standard operating procedure in system operation is to ensure safety of the people and machine. Our interpretation is that WRPC and KRPC are seemly in this aspect. Next in order of importance is equipment reliability with scale item number 23. A good number of equipment appears to be in good working condition but a major problem has been scale item no.15, political vicissitude, in order words changing leadership of the country goes with changes in the fortune of the organisation. Again, item 51 whose factor loading is 0.482 indicates that the leadership style appears to be deficient in grandeur and purposefulness.

Safely risk is scale item no. 25 and the corresponding factor loading of 0.624 is considered substantial. We cannot agree more that the refineries hardly have fire incident except for the scam of two years ago in WRPC

Nigerian Journal of Technology which did not result in any serious safety risk. The PCA model employed has singled item 34, infrastructure deficit, as the next in importance to safety risk. It seems that accumulated depreciation including obsolescence in technology is affecting the operations of the refinery and as such Turn Around Maintenance (TAM), which is item 38 appears not to be too important by virtue of the low rating 0.494 . Indeed TAM cannot be of much primacy when there is obvious technological obsolescence and this leads to unreliability of equipment. The implication is that the refinery is affected by age. Other important factors are manpower imbalance and manpower resource recruitment with scale items 44 and 53 respectively wielding corresponding factor loadings of 0.584 and 0.563. What is significant is that although the organization may have the right number of people but they appear not to have matching competences. Other variables include interest rate, paucity of investors, and business sustainability. The rest include properties acquisition, gas flaring, refinery planning, operation risk, cognate training and population encroachment. All these are important variables to be included in the first phase of planning for repositioning. The entire gamut of omnium-gatherum constitute elements of policy variables in case the organisation would organise for operational rebirth.

At this juncture, we take up another cluster which is organization's good will: Partnering alliance, gratification, maintenance, petroleum process technology and reputation as depicted in Table 5 constitute a bipolar factor.

Table 5: Organization's Good will

\begin{tabular}{lll}
\hline \multicolumn{2}{c}{ PC2: Organization's Goodwill } \\
\hline 11 & Partnering Alliance & -0.448 \\
16 & Gratification & 0.690 \\
26 & Maintenance & 0.522 \\
30 & Petroleum Process Technology & 0.418 \\
56 & Reputation & 0.536 \\
\hline
\end{tabular}

The respondent's evaluation of organisation's good will is well captured in the five some cluster creatively labelled as organisation's good will. It is a bipolar factor with four scale items wielding positive signs. Partnering alliance wields a factor loading of -0.448 . The import of the negativism is that the refinery management is not partnering or networking with similar refineries outside Nigeria with a view to copying positive development as being practised in other places. Gratification is scale item 16. It has the highest factor loading. In order words, the 
respondents could not agree more that standard ethical practices appear to be unwonted in the refineries. Scale item 26, wielding a factor loading of 0.522 , is a mediocre. It signifies that average attention is given to maintenance in the organization. But scale item 30 , refinery process technology, wields moderate factor loading. This signifies that the processing methodology adopted by NNPC is not the state-of-art technology. Finally, the reputation of the organisation is considered adequate by virtue of factor loading of 0.536 for scale item 26. Generally, the corporate deportment, correctitude, reputation quotient, carriage of Nigeria Refineries is at its best at all times. Like Fredrick Taylor said "give us the tools and we shall do the job". We believe that if WRPC and KRPC are seemly equipped and properly funded, they will do the job [23].

The next cluster creatively labelled economic condition is another bipolar factor.

\begin{tabular}{cll}
\multicolumn{3}{c}{ Table 6: Economic Condition } \\
\hline 1 & Funding & 0.485 \\
2 & Soaring price & 0.428 \\
3 & Competition & 0.469 \\
18 & Sanction & 0.475 \\
24 & Explosion Risk & 0.466 \\
47 & Motivation & $-0.522 \mathrm{q}$ \\
\hline
\end{tabular}

With the exception of scale item no. 47 , motivation, which has a negative factor loading of -0.522 , the rest four factors are moderately loaded. We know that payment in NNPC is very much higher than what obtains those in the civil service but judging by the negative loading, the impression is that motivation is low. Besides its well-known that reward motivates behaviour but reward may not necessary be monetary; it could be recognition or it could be in terms of challenging opportunities jobs offer. Jobs that offer little challenges are by themselves dull and unpleasant; they hardly afford job satisfaction. If this be the case, it's advised that management make jobs more productive and challenging. This factor has to be looked into. Our interpretation will be that, in part, lack of motivation might be that the work is not productive and challenging even though workers get good remuneration.

The scale item, soaring price, has factor loading of 0.428 . The factor loading indicates that the issue is fairly important. However, the soaring price arises on account of the fact that Nigeria exports crude and buys back refined products and that exposes Nigeria to market forces which tend to influence the high cost of the products in the domestic market. Competition, sanctions and explosion risks all have similar factor loadings representing economic condition.

However, further downstream, we have oligopolistic practices by few oil marketers which sometimes create artificial scarcity in order to create soaring prices. This oligopoly is both practised by independent and major marketers alike. Funding, that is, the no. 1 scale item, wielding a factor loading of 0.485 falls within the regime of middling. Our interpretation of this scale item, based on the factor loading, is that the organization is moderately funded by government but respondents appear to be undecided about the income and expenditure pattern in the organization. Again, sanction and explosion risk are also of moderately significance in the organization. Sanctions and explosion risk wield factor loadings of 0.475 and 0.466 respectively. Sanction such as prohibition of gas flaring is still loosely enforced to say the least while explosion risk appears to be an unwonted occurrence. Another important cluster is creatively labelled Nuggets of know-how.

\begin{tabular}{cll} 
Table 7: & Nuggets of know-how & \\
\hline 6 & Changes in demand & -0.415 \\
12 & Project Management Risk & 0.556 \\
29 & Maintenance Methodology & 0.405 \\
49 & Skills & -0.481 \\
\hline
\end{tabular}

It is another bipolar factor because the matrixes of the factor loadings are having negative and positive signs. Scale items nos. 6 and 49, changes in demand and skills respectively wield factor loadings of -0.415 and 0.481 respectively. The Nigerian consumers are in need of more products but there is no corresponding increase in supply. Marketers, who are importing the products, are not meeting demands, hence the negative value. More importantly, the refinery appears not to have the right know-how and the working plants to meet up with increase in demand and that appears to be the main reason decision to export crude and buy back the refined products. Equally, the refineries do handle certain projects and we know that risks skulls in stillness just like surprise waits in ambush. The middling factor loading which this scale item wields suggests that project management risks are classified as average importance.

Maintenance methodology: this scale item no. 29, has moderate loadings, suggesting that maintenance attention is given fair concern. Skills, serial no. 49, 
have negative factor loadings of -0.489 . The implication is that the skill to refine crude oil is lacking.

The next cluster is creatively labelled corporate overdrive.

Table 8: Corporate Overdrive

\begin{tabular}{lll}
\hline 39 & Process Safety & -0.451 \\
48 & Job Satisfaction & -0.419 \\
55 & Manpower Resource Availability & -0.585 \\
\hline
\end{tabular}

It is a lanky factor because all the variables have negative factor loadings. The implication is that extra effort is not being made in the area of process safety, job satisfaction, and manpower availability in order to achieve corporate goals.

Talking about supply chain management which encompasses three factors, market volatility, crude loading/unloading, and adequate manpower resource availability are negatively loaded as middling, suggesting that they are shadows of themselves.

\begin{tabular}{lll}
\multicolumn{3}{c}{ Table 9: Supply Chain Management } \\
\hline 5 & Market Volatility & -0.519 \\
40 & Loading/ Unloading & 0.492 \\
54 & Adequate Manpower Planning & -0.492 \\
\hline
\end{tabular}

It further suggests that the products are unsteadily available in the market while adequate manpower availability is a farce. Besides, loading of crude for export and unloading of refined product when they are imported do involve unavoidable delays. All these scale items are associated with supply chain of products distribution in Nigeria.

Villianousness of vandalism: This represents a bipolar dual factor.

Table 10: Villianousness of Vandalism

\begin{tabular}{lll}
\hline 58 & Insecurity/ Terrorism & -0.450 \\
60 & Legal Risk & 0.489 \\
\hline
\end{tabular}

The first reflects insecurity and terrorism. As a matter of fact, villians, for whatever reasons they have, disrupt pipelines bearing crude oil and gas for their own selfish motives. The factor loading on this issue wields a value of -0.450 suggesting that the issue is middling by PCA evaluation. The negative value show that, within the context of the cluster, the variable is destructive, and it is neither in the interest of the organization nor that of Nigeria. The issue needs to be addressed. On the other hand, legal risk is associated with havoc caused by the activities of villians. The effect of these villianous acts affect the communities in which they operate. The NNPC is held accountable for payment of compensation. The issue is thus a serious environmental pollution matter.

Seemly corporate culture: In this motley, effective monitoring and supervisory role is considered. NNPC should liaise with the relevant enforcement agency to reduce the menace of pipeline vadalization

Table 11: Seemly Corporate culture

\begin{tabular}{lll}
\hline 44 & Effective Supervision & -0.403 \\
59 & Environmental/Regulation & -0.568 \\
\hline
\end{tabular}

Miscellany: PC 12 - PC 19

This breed is a lanky factor because they all wield negative values.

Table 12: Miscellany

\begin{tabular}{|l|l|l|}
\hline \multicolumn{3}{|c|}{ PC12 } \\
\hline 10 & Relevant Linkages & -0.407 \\
\hline \multicolumn{3}{|c|}{ PC13 } \\
\hline 22 & Refinery Complete Automation & -0.414 \\
\hline \multicolumn{3}{|c|}{ PC19 } \\
\hline \multicolumn{3}{|c|}{ Pipeline Vandalism } \\
\hline
\end{tabular}

The import is that there appears not to be adequate networking of existing facilities, infrastructure and other facilities. These resources need to be optimally utilized. Again, the refinery operations need to be automated. Since this idea is yet to be implemented, it is loaded as negative factor.

Finally, we examine pipeline vandalization. We have stated from the foregoing, the negative dimension which the actors -villains - perpetrate. But that's a longer matter for another time.

\section{RECOMMENDATIONS}

Arising from the foregoing analysis, the following recommendations are offered:

i. Government should be mindful of the personalities that are appointed into the ministerial and Board positions.

ii. Government should hold fast to the vision and mission of KRPC and WRPC that should sustain its purpose of creation optimally and efficiently.

\section{CONCLUSION}

At the onset, we set out the objective of this study to identify the gamut of factors that impact on the operation of the NNPC especially the WRPC. The study further tries to appraise the inter correlation among these variable. To this end, our results show that the 
variables identified are multifaceted and substantial correlation exist among them. These correlations have been found significant in the area of policy articulation for dealing with the research problem.

\section{REFERENCES}

[1] Aodu K. "Performance of Nigerian Refineries" www.vangardngr, Accessed on August15, 2015.

[2] Sylvester, I. " Greenfield Refinery Initiative" www.nnpc.com/nnpcbusiness/midstreamventures Lgreenfieldrefineryinitiative", Accessed on May, 2014

[3] Zhen, Y., Young, M., and Shao, Z. "Research Group of energy Policy Institute of Qualitative and Technical Economics", www.energygroup/policy, Accessed on june,20, 2013.

[4] Li, W. "Modelling of oil Refinery for Production Planning, Scheduling and Economic Analysis" http://en.wikipedia/wiki/Hong Hong uniersity of - Science and_Technology, Accessed onNovember 20, 2015.

[5] Moro, L.F.L.,'Mixed-Integer Linear Programming Techniques for Planning and Short Term Scheduling of Oil Refineries", www5.usp.br/english/?Lang, Accessed on September 25, 2014.

[6] Isa, A. H. I., Hamisu, S., Lamin,H. S., Ya'u M. Z. and Olayande, J. S. "Energy Planning and Analysis" Academic Journal, vol. 4, Number 7, 2013, pp 184187,

[7] Uhunmwuan S.O. "Policy of Deregulation and Libralization of the Downstream Oil Sector in Nigeria: the implication on the Nigeria Economy in

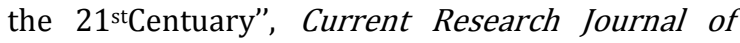
Economic Theory, vol.4, Number.4, 2012 pp. 112119

[8] Ejikeme-Ugwu E. "Planning for the integrated refinery subsystems", www.cranfield.co.uk, Accessed September25, 2014

[9] JOLY, M., MORO, L. F. L. and PINTO, J. M. "Planning and scheduling for petroleum refineries using mathematical programming", Brazil Journal of Chemical Engineering, Vol. 19, 2002, pp 207-228.

[10] Lee, H., Pinto, J. M., Grossmann, I. E. and Park, S. "Mixed Integer Linear Programming Model for Refinery Short-Term Scheduling of Crude Oil Unloading with Inventory Management", Industrial and Engineering Chemistry Research, vol. 35, 1996, pp $1630-1641$.

[11] Alaneme, E.C and Igboanugo, A.C."A Factorial Study on the Inherent Risks of Nigeria Marginal Oilfields, Research", Journal of Applied Sciences, Engineering and Technology, Vol. 6, Number 3, 2013 pp 468476 ,
[12] Ribas, G.P., Leiras, A. and Hamacher, S. "Operational Planning of Oil refineries under uncertainty special issue: Applied stochastic optimization", IMA Journal of Management Mathematics, vol. 3, 2012, pp 394412.

[13] Khor, C.S and Elkame, A. Optimization Strategies. Petroleum Refinery Planning under Uncertainty, Verlag, V.D.M. and Muellere,K. Publishing House, 2009.

[14] Okumroumu, T. 0. "Deregulation of the downstream sector of the Oil Industry in Nigeria: Analysis of some main issues", The C.B.N Bullion, Vol. 28, Number 4, 2004 pp 60-68.

[15] Otaru, A.J., Abdulkareem, A.S., Yusuf, Y.R., Odigure, J.O., Okafor, J.O. and Ibrahim, S."Evaluation of Safety in a Petroleum Refining Company: A Case Study on the Naphtha Hydro - Treating Unit (Nhu) Of Kaduna Refining and Petrochemical Company, Nigeria", IOSR Journal of Environmental Science, Toxicology and Food Technology, Vol. 3, Number 5, 2013, PP 68-82.

[16] Prabhakar, D.P and Raj, J. V. P. "A New Model for Reliability Centered Maintenance in Petroleum Refineries", International Journal of Science \& Technology Research, Vol. 2, 2013, pp 56-72.

[17] Khor, C.S \&Elkamel, A. Optimization Strategies: Petroleum Refinery Planning under Uncertainty, VDM Verlag and Mueller K. Publishing House, 2009

[18] Ogedegbe, A.O.' 'The Nigerian Refineries: History, Problems and Possible Solutions" ,www.Onlinenigeria.com, Accessed on September $25,2014$.

[19] Cheng, S. K. (2013), A Hybrid of Stochastic Programming Approaches with Economic and Operational Risk Management for Petroleum Refinery Planning under Uncertainty, Khnxhwa, Mara3NH

[20] Ogbuanu, U. C."Federal Government to remove N1.5tr Petroleum Subsidy" www.Onlinenigeria.com/ Accessed on August 10, 2014.

[21] Sylvester, I. "Greenfield Refinery Initiattive and Subsidy Payment", www.nnpcgroup.com /NNPCBusiness/Midstream Ventures/ Greenfieldrefinery Accessed on November 30, 2014.

[22] Legendre, P."Species Association: The Kendal Coefficient of Concordance Revisited", Journal of Agriculture, Biological and Environmental Statistics, Vol. 10, Number. 2, 2005, pp 226 - 245

[23] Okere, R."Nigeria's Refining Capacity, the quest for self-sufficiency", www.theguardian.com, Accessed on December 10, 2015. 